\title{
Study of Antimicrobial Activity of Medications for Wound Treatment
}

Boyko N. Nick', Zaytsev I. Alexander ${ }^{1}$, Osolodchenko P. Tatyana ${ }^{2}$, Melnik L. Anatoly ${ }^{2}$, Nevmerzhitskiy V. Vitaliy $^{2}$, Volkov O. Taras ${ }^{2}$ and Kazmirchuk V. Victor ${ }^{2}$

1. Department of Processes and Devices of Chemical-Pharmaceutical Industries, National Pharmaceutical University, Kharkov, 61140 Ukraine

2. Biochemistry and Biotechnology Laboratory and Antibacterial Agents Laboratory, State Institution I.I. Mechnikov Institute of Microbiology and Immunology of the National Academy of Medical Sciences of Ukraine, Kharkov, 61057 Ukraine

\begin{abstract}
This paper presents data on the study of antimicrobial activity of 16 medications used for wound treatment. Antimicrobial activity of medications has been studied by well diffusion method on standard microorganism test strains: $S$. aureus ATCC 25923, E. coli ATCC 25922, $P$. aeruginosa ATCC 27853, P. vulgaris ATCC 4636, B. subtilis ATCC 6633, and C. albicans ATCC 885/653. Integrated indexes of antimicrobial activity of medications using vector theory have been calculated, which allowed to place most active of them in the order of descending activity: Levomecolum $A=2.73, r^{2}=0.82 ;$ Levosin $A=$ 2.41, $r^{2}=0.83$; Synthomycinum $A=2.33, r^{2}=0.97$; Methyluracilum cum myramistino $A=2.31, r^{2}=0.83$; Oflocainum-Darnitsa $A=2.25, r^{2}=0.97$; and Betadine $A=2.03, r^{2}=0.97$. The mean of integrated indexes of antimicrobial activity and the square of the correlation coefficient for the group of these medications are as follows: $A=2.02$, and $r^{2}=0.91$. Comparison of mean values of integrated indexes of antimicrobial activity of medicines for wound treatment with those of water-alcohol extracts from plant raw material containing alkaloids, tannins, hydroquinone, naphthoquinones, anthraquinones, and phenols has shown to be promising of further development of domestic agents having antimicrobial activity based on water-alcohol extracts from plant raw material.
\end{abstract}

Key words: Antimicrobial activity, wound medications, well diffusion method.

\section{Introduction}

Injuries, wounds, skin burns, and postoperative stitches, are often accompanied by penetration of pathogenic and opportunistic microorganisms, as well as development of infectious complications, both local and systemic ones. So, for example, in case of surgical wounds, the frequency of inflammatory complications may vary from 1 to $30 \%$ depending on aseptic conditions, patient's state, type and quantity of the infectious agent, etc. [1, 2]. In this connection, prevention and treatment of the infectious process is very important.

At present, treatment of deep wounds is carried out

Corresponding author: Boyko N. Nick, cand. pharm. sc., associate professor, research field: technology of medications (phytotechnology). E-mail: boykoniknik@gmail.com. comprehensively, using both general therapeutic methods (surgery, systemic antibiotic therapy) and local ones (topical application: antimicrobial agents in the form of ointments, gels, liniments, ultrasound therapy, laser therapy, ultrahigh-frequency therapy, etc.). Treatment of superficial wounds in most cases is accompanied only by topical application of antimicrobial agents.

Thus, antimicrobial medications for topical application are of great importance for treatment of infectious wounds.

The purpose of this work is to study antimicrobial activity of commercially available medications used for treatment of wounds and comparison of integrated indexes with those of water-ethanol extracts from plant raw material. 


\section{Material and Methods}

Antimicrobial activity of medications was determined using AWD (agar well diffusion method), with determination of microorganism growth inhibition zone diameters. The following test strains of microorganisms were used for evaluation of antimicrobial activity of medications: $S$. aureus ATCC 25923, E. coli ATCC 25922, P. aeruginosa ATCC 27853, P. vulgaris ATCC 4636, B. subtilis ATCC 6633, and C. albicans ATCC 885/653.

The microbial burden was $10^{7}$ colony forming units per $1 \mathrm{~mL}(\mathrm{CFU} / \mathrm{mL})$ of the medium and was determined in accordance with McFarland standard. 18-24-hour microorganism culture was taken into work. Mueller-Hinton agar and MPA were used for bacteria. Agar Sabouraud was used for Candida albicans.

The following criteria were applied when evaluating antibacterial properties of antibacterials:

(1) Absence of microorganism growth inhibition zones around the well, as well as inhibition zones up to $10 \mathrm{~mm}$, indicates to the fact that the microorganism is not sensitive to the antibacterial studied or its concentration;

(2) Presence of growth inhibition zones with diameter of $10-15 \mathrm{~mm}$ indicates to low sensitivity to the antibacterial studied or its concentration;

(3) Presence of growth inhibition zones with diameter of $15-25 \mathrm{~mm}$ is regarded as an indicator of microorganism sensitivity to the antibacterial concentration studied;

(4) Presence of growth inhibition zones, the diameter of which exceeds $25 \mathrm{~mm}$, indicates to high sensitivity of microorganisms to the antibacterial studied or its concentration.

For comparison of the antimicrobial activity preparations between themselves, calculating an average value group of identical preparations and preparation selection of the most active among these authors used vector theory.

Vector theory makes it possible to present antimicrobial activity of the medication on the basis of single test strains of microorganisms as a unified vector in n-dimensional space. In this case, the vector is characterized by the following: $A$-integrated index of antimicrobial activity (describes the "strength" of antimicrobial activity of the medication); $r^{2}$-the square of the correlation coefficient (describes the spectrum of action of the medication on test strains of microorganisms studied), its range of values is from 0 to 1 [3].

Calculation of the integral index antimicrobial activity of medicinal product and its error was performed using the following formulas:

$$
\begin{gathered}
A=\sqrt{\left(a_{1} \cdot \frac{D_{1}}{25}\right)^{2}+\ldots+\left(a_{6} \cdot \frac{D_{6}}{25}\right)^{2}} \\
\Delta A=\sqrt{\left(\frac{a_{1}^{2} \cdot D_{1} \cdot \Delta D_{1}}{25^{2}}\right)^{2}+\ldots+\left(\frac{a_{6}^{2} \cdot D_{6} \cdot \Delta D_{6}}{25^{2}}\right)^{2}}(2)
\end{gathered}
$$

where $A$ is a complex index antimicrobial activity of medication, dimensionless value, (index efficiency ranges: 1.0-1.5 the medicinal product has weak antimicrobial activity; $1.5-2.5$ the medicinal product has medium antimicrobial activity; more than 2.5 the medicinal product has strong antimicrobial activity);

$a_{1}, a_{2}, a_{3}, a_{4}, a_{5}, a_{6}$ are weighing coefficients of microorganism strain significance in the disease, in order to simplify, we took them as a one unit, however, application data from the research of prevalence degree of microorganisms in affected people can also be used;

$D_{1}, \ldots D_{6}$ and $\Delta D_{1}, \ldots \Delta D_{6}$ are diameters and their errors of growth inhibition zone of the examined microorganism strains: S. aureus ATCC 25923, E. coli ATCC 25922, P. aeruginosa ATCC 27853, $P$. vulgaris ATCC 4636, B. subtilis ATCC 6633, and $C$. albicans ATCC 885/653, mm;

25 is a virtual indicator of the microorganism growth inhibition zone, in $\mathrm{mm}$, that has an optimal value (between medium and strong sensitivity), however, an indicator of conventional medicinal 
product for the certain strain may be used under the same determination conditions, as medicinal products studied;

$\Delta A$ is an error of the complex index antimicrobial activity of medicinal product.

For comparison of A (research) and B (standard) objects/drugs (vectors) with each other, cosine of the angle between them, which equals correlation coefficient $r$ and denotes linear connection power between the parameters in mathematical statistics, may also be used, apart from their absolute value (size). Square of correlation coefficient $\left(r^{2}\right)$ denotes objects (vectors) similarity level. Correlation coefficient (cosine of the angle) between vectors may be calculated using the following Eq (3):

$$
\cos \gamma=r=\frac{\sum\left[a_{i}^{A} \cdot D_{i}^{A} \cdot a_{i}^{B} \cdot D_{i}^{B}\right]}{\sqrt{\sum\left[a_{i}^{A} \cdot D_{i}^{A}\right]^{2}} \cdot \sqrt{\sum\left[a_{i}^{B} \cdot D_{i}^{B}\right]^{2}}}
$$

Statistical processing of the results has been conducted in accordance with the SPhu (State Pharmacopoeia of Ukraine) with confidence level of 0.95 and number of degrees of freedom of 5 [4].

The calculation of the integrated indexes of medications' antimicrobial activity was performed using Eqs (1)-(3) in accordance with the information paper of the Ministry of Health of Ukraine No. 65-2015 "method of integral assessment of antibacterial activity of medications" [5].

The studies were carried out during 2014-2015; for this purpose the following medications available in the pharmaceutical market of Ukraine were chosen [6]:

Balsamic Liniment (by Vishnevsky), PJSC SIC Borshchahivskiy CPP, Kiev, Ukraine, No. 1010914, expiration date 10/2019, $40 \mathrm{~g} /$ pack, content per $1 \mathrm{~g}$ : bismuth tribrpmphenolate- $30 \mathrm{mg}$; birch tar-30 mg;

Betadine ointment, Egis Pharmaceutical plant, Hungary, No. 665N1013, expiration date 10/2016, 20 $\mathrm{g} /$ pack, content per $1 \mathrm{~g}$ : povidone-iodine $-100 \mathrm{mg}$;

Laevomecol ointment, PJSC SIC Borshchahivskiy
CPP, Kiev, Ukraine, No. 1551014, expiration date 11/2016, 40 g/pack, content per $1 \mathrm{~g}$ : chloramphenicol-7.5 mg, methyluracil $-40 \mathrm{mg}$;

Laevosinum ointment, JSC Nizhpharm, the Russian Federation, Nizhniy Novgorod, No. 350414, expiration date 05/2016, $40 \mathrm{~g} / \mathrm{pack}$, content per $1 \mathrm{~g}$ : chloramphenicol-10 mg, sulfodimetoxin - $40 \mathrm{mg}$, methyluracil $-40 \mathrm{mg}$, trymecain $-30 \mathrm{mg}$;

Methyluracilum cum myramistino ointment, PLC Darnitsa Pharmaceutical company, Kiev, Ukraine, No. ML 41013, expiration date 11/2015, 15 g/pack, content per $1 \mathrm{~g}$ : methyluracil $-50 \mathrm{mg}$, myramistin -5 $\mathrm{mg}$;

Myramistinum-Darnitsa ointment, PLC Darnitsa Pharmaceutical company, Kiev, Ukraine, No. MR 10514, expiration date 06/2016, $15 \mathrm{~g} / \mathrm{pack}$, content per $1 \mathrm{~g}$ : myramistin $5 \mathrm{mg}$;

Oflocainum-Darnitsa ointment, PLC Darnitsa Pharmaceutical company, Kiev, Ukraine, No. MF 90514; expiration date 06/2016, $15 \mathrm{~g} / \mathrm{pack}$, content per $1 \mathrm{~g}$ : oflocain-1 mg; lidocaine-30 mg;

Panthestin-Darnitsa gel, PLC Darnitsa Pharmaceutical company, Kiev, Ukraine, No. GP60614; expiration date 07/2016, 15 g/pack, content per $1 \mathrm{~g}$ : dexpanthenol $-50 \mathrm{mg}$; myramistin $-5 \mathrm{mg}$;

Povidone-Iodine liniment, PJSC SIC Borshchahivskiy CPP, Kiev, Ukraine, No. 030714, expiration date 08/2016, $30 \mathrm{~g} / \mathrm{pack}$, content per $1 \mathrm{~g}$ : povidone-iodine-100 $\mathrm{mg}$;

Ranostop ointment 10\%, PJSC Phytopharm, Artemivsk, Ukraine, No. 10714, expiration date 07/2016, 40 g/pack, content per 1 g: povidone-iodine- $100 \mathrm{mg}$;

Sanoderm cream, JSC Kievmedpreparat, Arterium Corporation, Kiev, Ukraine, No. 91014, expiration date 10/2017, $15 \mathrm{~g} / \mathrm{pack}$, content per $1 \mathrm{~g}$ : bethamethazone dipropionate $-0.64 \mathrm{mg}$, gentamicin sulfate $-1.0 \mathrm{mg}$, clotrimazole $-10 \mathrm{mg}$;

Synthomycinum liniment, JSC Nizhpharm, the Russian Federation, Nizhniy Novgorod, No. 490614, expiration date 07/2016, $25 \mathrm{~g} / \mathrm{pack}$, content per $1 \mathrm{~g}$ : 
chloramphenicol—100 mg ;

Unguentum sulfuratum simplex, Viola Pharmaceutical plant, Zaporizhzhia, Ukraine, No. 061114; expiration date 11/2016, 25 g/pack, content per $1 \mathrm{~g}$ : sulfur- $0.33 \mathrm{~g}$;

Tetracyclinum unguentum, JSC Nizhpharm, the Russian Federation, Nizhniy Novgorod, No. 221213, expiration date 01/2017, $15 \mathrm{~g} /$ pack, content per $1 \mathrm{~g}$ : tetracycline hydrochloride $-30 \mathrm{mg}$;

Triacutan ointment, JSC Kievmedpreparat, Arterium Corporation, Kiev, Ukraine, No. 90914, expiration date 09/2016, $15 \mathrm{~g} /$ pack, content per $1 \mathrm{~g}$ : bethamethazone dipropionate $-0.64 \mathrm{mg}$, gentamicin sulfate $-1.0 \mathrm{mg}$, clotrimazole $-10 \mathrm{mg}$;

Triacutan cream, JSC Kievmedpreparat, Arterium Corporation, Kiev, Ukraine, No. 170914, expiration date 09/2017, 15 g/pack, content per 1 g: bethamethazone dipropionate $-0.64 \mathrm{mg}$, gentamicin sulfate- $1.0 \mathrm{mg}$, clotrimazole $-10 \mathrm{mg}$.

\section{Results and Discussion}

Results of the study of antimicrobial agents for wound treatment are presented below in Table 1 .

As it may be seen from the results of Table 1, some medications, namely: Balsamic Liniment (by Vishnevsky), Panthestin-Darnitsa gel, Ungventum sulfuratum simplex, and Triacutan, did not exhibit antibacterial activity. It may be due to the hydrophobic base of these products, which does not let substances diffuse into hydrophilic agar when using AWD method.

Medications based on cation-active antiseptic miramistin demonstrated rather ambiguous activity in our studies. Myramistinum-Darnitsa ointment with one-component composition had an action on all the strains studied. Methyluracilum cum myramistino ointment had no action on Candida albicans. Panthestin-Darnitsa gel showed no antimicrobial activity according to AWD method, which is probably associated with presence of the second component-panthenol, which can stimulate bacteria growth and neutralize antimicrobial properties of miramistin, however, it is only a hypothesis.

Based on antimicrobial activity of medications for local treatment of wounds from Table 1 and vector theory, integrated indexes of antimicrobial activity and the square of correlation coefficient were calculated in Table 2.

Table 1 Antimicrobial activity of the medications for the topical treatment of wounds studied by AWD method.

\begin{tabular}{|c|c|c|c|c|c|c|}
\hline \multirow[b]{2}{*}{ Name of the medicine } & \multicolumn{6}{|c|}{ Diameters of growth inhibition zones in mm; repeat count, $n=6, P=0.95$} \\
\hline & $\begin{array}{l}\text { S. aureus } \\
\text { ATCC } 25923\end{array}$ & $\begin{array}{l}\text { E. coli ATCC } \\
25922\end{array}$ & $\begin{array}{l}P . \text { aeruginosa } \\
\text { ATCC } 27853\end{array}$ & $\begin{array}{l}P . \text { vulgaris } \\
\text { ATCC } 4636\end{array}$ & $\begin{array}{l}\text { B. subtilis } \\
\text { ATCC } 6633\end{array}$ & $\begin{array}{l}\text { C. albicans } \\
\text { ATCC } 885 / 653\end{array}$ \\
\hline Balsamic liniment & growth & growth & growth & growth & growth & growth \\
\hline Betadine ointment & $23.8 \pm 0.5$ & $19.9 \pm 0.7$ & $18.6 \pm 0.8$ & $17.8 \pm 0.5$ & $26.0 \pm 0.6$ & $16.4 \pm 0.8$ \\
\hline Laevomecol ointment & $33.7 \pm 0.6$ & $23.0 \pm 0.5$ & $29.3 \pm 0.7$ & $30.4 \pm 0.6$ & $34.7 \pm 0.8$ & growth \\
\hline Laevosinum ointment & $28.3 \pm 0.5$ & $26.1 \pm 0.6$ & $27.6 \pm 0.4$ & $28.0 \pm 0.9$ & $24.7 \pm 0.7$ & growth \\
\hline $\begin{array}{l}\text { Methyluracilum cum } \\
\text { Myramistino ointment }\end{array}$ & $27.7 \pm 0.4$ & $28.8 \pm 0.7$ & $23.6 \pm 0.6$ & $23.2 \pm 0.5$ & $25.4 \pm 0.9$ & growth \\
\hline Myramistinum-Darnitsa ointment & $17.6 \pm 0.7$ & $16.3 \pm 0.4$ & $15.4 \pm 0.5$ & $14.7 \pm 0.6$ & $17.8 \pm 0.7$ & $20.3 \pm 0.5$ \\
\hline Oflocainum-Darnitsa ointment & $25.6 \pm 0.8$ & $22.3 \pm 0.5$ & $20.5 \pm 0.7$ & $24.2 \pm 0.4$ & $27.4 \pm 0.6$ & $16.3 \pm 0.7$ \\
\hline Panthestin-Darnitsa gel & growth & growth & growth & growth & growth & growth \\
\hline Povidone-Iodine liniment & $17.0 \pm 0.6$ & $16.7 \pm 0.9$ & $23.1 \pm 0.8$ & $19.8 \pm 0.7$ & $20.3 \pm 0.5$ & $20.1 \pm 0.4$ \\
\hline Ranostop ointment & $18.4 \pm 0.4$ & $15.2 \pm 0.7$ & $14.9 \pm 0.4$ & $14.7 \pm 0.9$ & $20.3 \pm 0.6$ & $17.6 \pm 0.7$ \\
\hline Sanoderm cream & $14.7 \pm 0.8$ & $14.1 \pm 0.9$ & $18.3 \pm 0.7$ & $14.0 \pm 0.6$ & $24.3 \pm 0.8$ & $13.2 \pm 0.6$ \\
\hline Unguentum sulfuratum simplex & growth & growth & growth & growth & growth & growth \\
\hline Synthomycinum liniment & $24.7 \pm 0.7$ & $21.4 \pm 0.8$ & $18.3 \pm 0.9$ & $19.3 \pm 0.6$ & $30.7 \pm 0.5$ & $26.2 \pm 0.4$ \\
\hline Tetracyclinum unguentum & $29.3 \pm 0.6$ & $15.0 \pm 0.8$ & growth & growth & $18.6 \pm 0.7$ & $14.7 \pm 0.5$ \\
\hline Triacutan ointment & growth & growth & growth & growth & growth & growth \\
\hline Triacutan cream & $15.7 \pm 0.5$ & $15.3 \pm 0.7$ & $17.7 \pm 0.4$ & $15.7 \pm 0.6$ & $20.3 \pm 0.5$ & $16.3 \pm 0.8$ \\
\hline
\end{tabular}


Table 2 Integrated indexes of antimicrobial activity of the medications studied calculated by the method vector theory.

\begin{tabular}{lll}
\hline Name of the medication & Integrated index of antimicrobial activity, $A$ & The square of correlation coefficient*, $r^{2}$ \\
\hline Balsamic liniment & 0 & 0 \\
Betadine ointment & $2.03 \pm 0.03$ & 0.97 \\
Laevomecol ointment & $2.73 \pm 0.03$ & 0.82 \\
Laevosinum ointment & $2.41 \pm 0.03$ & 0.83 \\
Methyluracilum cum myramistino ointment & $2.31 \pm 0.03$ & 0.83 \\
Myramistinum-Darnitsa ointment & $1.68 \pm 0.02$ & 0.99 \\
Oflocainum-Darnitsa ointment & $2.25 \pm 0.03$ & 0.97 \\
Panthestin-Darnitsa gel & 0 & 0 \\
Povidone-Iodine liniment & $1.92 \pm 0.03$ & 0.99 \\
Ranostop ointment & $1.66 \pm 0.03$ & 0.98 \\
Sanoderm cream & $1.65 \pm 0.03$ & 0.95 \\
Unguentum sulfuratum simplex & 0 & 0 \\
Synthomycinum liniment & $2.33 \pm 0.03$ & 0.97 \\
Tetracyclinum unguentum & $1.62 \pm 0.03$ & 0.61 \\
Triacutan ointment & 0 & 0 \\
Triacutan cream & $1.66 \pm 0.02$ & 0.99 \\
Mean & $1.52 / 2.02 * *$ & $0.68 / 0.91 * *$ \\
\hline
\end{tabular}

* Results of correlation coefficient are shown with consideration for Eq (3), in which virtual indexes, accepted throughout all the strains of $25 \mathrm{~mm}$, are supplied instead of real indexes of growth inhibition zones for comparison of medications.

** Mean values of the integrated index of the numerator are calculated taking into account values of hydrophobic-base medications, whereas those in the denominator-without taking these values into account.

As it is seen from Table 2, the mean value of integrated indexes of medications for wound treatment in the form of soft medicines are at the middle level of antimicrobial activity, $A=1.52 / 2.02$ and $r^{2}=$ 0.68/0.91 (with consideration for indexes of hydrophobic-base medicines/without consideration). This makes it possible to focus on these indexes in the further development of new medications.

It should be noted that the following medications were the most active: Betadine, Levomecolum (of Borshchahivskiy CPP), Levosin, Methyluracilum cum myramistino, Oflocainum-Darnitsa, and Synthomycinum.

When comparing the means of integrated indexes of antimicrobial activity of medications for wound treatment studied with those of water-alcohol extracts from plant raw material containing: hydroquinones, naphthoquinones, anthraquinones $A=1.77, r^{2}=0.87$; tannins $A=1.56, r^{2}=0.79$; alkaloids $A=1.61, r^{2}=$ 0.79 ; phenols which have been published previously [7-10], it can be seen that medications based on extracts from plant raw material could be a good alternative to synthetic ones. It should be also noted that water-alcohol extracts were prepared at a ratio of plant raw material and the extractant of 1:7 (w/v), which is higher than the recommended by SPhu (1:5), and that the extracts of plant raw material have additional pharmacological effects (wound-healing, anti-inflammatory, antioxidant, etc.).

\section{Conclusions}

We have determined antimicrobial activity of sixteen medications used for the topical treatment of wounds. The most activity was showed by the following medications: Betadine, Levomecolum, Levosin, Methyluracilum cum myramistino, Oflocainum-Darnitsa, and Synthomycinum.

Comparison of mean values of integrated indexes of antimicrobial activity of medicines for wound treatment with those of water-alcohol extracts from plant raw material containing alkaloids, tannins, hydroquinone, naphthoquinones, anthraquinones, and phenols has shown to be promising of further development of domestic agents having antimicrobial 
activity based on water-alcohol extracts from plant raw material.

\section{References}

[1] Salmanov, A. G. 2008. "Importance of Wound Microbial Contamination at Development of Infection in the Area of Surgical Intervention." Ukrainian Journal of Experimental Medicine by G. O. Mozhaev 1 (9): 6-8.

[2] Volkov, A. O., and Bolshakova, G. M. 2009. "The Microflora of Purulent Wounds and Modern Approaches on the Use of Antiseptics in Surgical Practice. Literature Review." Annals of Mechnikov Institute 2: 19-23.

[3] Boyko, N. N., Zaytsev, A. I., and Osolodchenko, T. P. 2014. "Vector Algebra Theory in Analysis of Properties of Antibacterial Medications." Annals of Mechnikov Institute 1: 20-6.

[4] State Pharmacopoeia of Ukraine. 1st ed. 2004. State Enterprise "Scientific and Expert Pharmacopoeias Centre.”. Kharkov: RIREH. Appendix 1: 520.

[5] Zaytsev, O. I., Yakovleva, L. V., Boyko, M. M., Pokhil, S. I., Osolodchenko, T. P., Hushylyk, B. I., Melnik, A. L., Nevmerzhitskiy, V. V., Hristyan, G. Je., Yudin, I. P., Makarenko, V. D., and Kazmirchuk, V. V. 2015. The Method of Integral Evaluation of Antimicrobial Activity of Drugs. Kiev: Newsletter of Innovations in Health Care. Ministry of Health Care of Ukraine. Ukrainian Centre for Scientific Health Information and Patent Licensing Work
(Ukrmedpatentinform), 65: 4.

[6] Cokolenko, O. I., Levchenko, M. Yu., Kuzub K. V., and Soboleva I. V. Internet-Project "Compendium on Line". Accessed February 1, 2015. http://compendium.com.ua.

[7] Boyko, N. N., Zaytsev, A. I., and Osolodchenko T. P. 2014. "Screening of Antimicrobial Properties of Ethanolic Extracts from Some Kinds of Raw Materials with Quinonderivatives." Annals of Mechnikov Institute 4: 67-72.

[8] Boyko, N. N., Zaytsev, A. I., and Osolodchenko, T. P. 2015. "Determination of Antimicrobial Activity of Ethanolic Extracts from Some Kinds of Raw Materials with Tannins." Annals of Mechnikov Institute 1: 49-54.

[9] Boyko, N. N., Zaytsev, A. I., and Osolodchenko, T. P. 2015. "Screening of Antimicrobial Activity of Ethanolic Extracts from Raw Materials Containing Alkaloids." Journal of Chemical and Pharmaceutical Research 7 (5): 160-6.

[10] Kazmirchyk, V. V., Volianskyi, Yu. L., Volianskyi, A. Yu., Liashenko, M. I., Spyrydonov, A. V., Voropai, A. Yu., Valchuk, S. I., Shatylo, Yu. V., Volkov, A. O., Kuchma, I. Yu., Yevsiukova, V. Yu., Sorokoumova, L. K., Koniukhov, I. V., Makarenko, V. D., Andreeva, I. D., Hryhorchuk, O. A., and Mizin, V. V. 2010. "The Use of Hop Alcohol Extract as an Active Substance Is Offered at Making of Pharmaceutical Compositions with Antimicrobial Action." Patent of Ukraine 2010, bul. 19: 4. 